\title{
The Effects of Water-based Insulation Paint Applied to Laminate Flooring Panels on the Thermal Conductivity Coefficient and Adhesion Resistance
}

\begin{abstract}
Ali Kabakci, ${ }^{a}$ and Haci İsmail Kesik ${ }^{\text {b,* }}$
In an effort to reduce negative feedback resulting from temperature fluctuations, house floors are commonly laid with laminate flooring. The aim of this study was to study the thermal insulation properties and adhesion strength of the water-based insulation paint mixed with hollow glass spheres and applied onto the laminate flooring. The objective was to determine whether a prepared insulation paint mixture can be used instead of backing paper. For this purpose, two different laminate flooring samples were used. In the first case, the upper surface of the sample was coated with decorative paper and the lining surface was coated with backing paper. The upper surface of the second sample was coated with decorative paper and the lining surface was not coated with backing paper. Then, insulation paint mixture was applied 2, 4, or 6 times to the lining surfaces of both groups, and experimental results were obtained. As the number of layers was increased, the insulation mixture applied to the lining surfaces of the test samples was found to contribute positively to thermal insulation and adhesion resistance of specimens.
\end{abstract}

Keywords: Format; Laminate flooring; Water-based insulation paint; Hollow glass microspheres; Thermal conductivity coefficient; Adhesion resistance

Contact information: a: Department of Furniture and Interior Design, Incirli Technical High School, Ankara, 06010, Turkey; b: Department of Forest Industrial Engineering, Faculty of Forestry, Kastamonu University, Kastamonu, 37150, Turkey; *Corresponding author: hismailkesik@kastamonu.edu.tr

\section{INTRODUCTION}

People express their lifestyles by covering the ceilings, walls, and floors in places where they live, and the consumers expect the heat insulation to be sufficient. Notably, the cold conductivity from the ground has made the floor coverings indispensable with regard to thermal insulation. In many countries of the world, as in Turkey, coatings and finishes are produced from different materials (Döngel et al. 2008; Kaymakcı et al. 2014). The high cost of solid wood, dimensional change at different ratios in three directions (radial, tangent, and longitudinal), and some other disadvantages of wood, such as the difficulty of providing different colors and patterns, has provided motivation to consider composite wood flooring (laminate flooring) (As 1998). The use of composite floors has brought along some advantages such as not requiring varnish and paint on the upper surface, good abrasion resistance, easy installation, and thermal insulation. However, the contribution of this application to thermal insulation is not at the desired level yet. In order to improve the thermal insulation properties of laminate floorings, which are lower cost than in solid wood materials (Sahin Kol et al. 2010; Uysal et al. 2011), low density and interstitial materials are reinforced into the middle layer and lining layers of laminate flooring. 
There are many studies on the thermal insulation properties of composite materials, wood panels, and protective layers supported by different nano materials. Composite materials treated with different coatings (paper, PVC, etc.) and preservatives (paint, varnish, etc.) have thermal conductivity values that vary depending on the concentration of chemicals used in them (Acik and Tutus 2012; Ustaomer and Usta 2017; Sahin and Dongel 2018). Another material developed for isolation is water-based isolation paint, which contains additives such as micro-sized hollow glass spheres. Currently, these kinds of applications are used for interior and exterior facades of buildings for thermal, acoustic, and moisture isolation (Wang et al. 2014; Posmyk 2016; Kimetsan 2018). The use of waterbased paints that are reinforced by micro-sized hollow glass spheres in floor coverings and the investigation of their heat insulation properties can contribute to the flooring industry.

It is important to know the thermal conductivity coefficient in the evaluation of the performance of thermal insulation materials (Zhou et al. 2013), and a low conductivity coefficient is one of the desirable features (Nemli and Kalaycioglu 2002; Lan et al. 2014). Further enhancement of the porous structure positively influenced the thermal performance of water-based paints reinforced by micro-sized hollow glass spheres (Dzyazko and Konstantinovsky 2014; Wang et al. 2014). The thermal conductivity values of the paints based on thicknesses of 0.10 to $0.18 \mathrm{~W} / \mathrm{mK}$ have been reported (Chukhlanov et al. 2017). The thermal conductivity coefficient values of WBNTP-D45 at the dry film thickness are 0.017 to $0.022 \mathrm{~W} / \mathrm{mK}$ (Tech. Rep. 12010 ) and demonstrate that $72{ }^{\circ} \mathrm{C}$ on one surface of the test device is measured at $36{ }^{\circ} \mathrm{C}$ on the other surface (Oztin 2014). In some studies, the thermal conductivity values of hollow water-based paints are quite different from each other and it has been reported that academic circles cannot reach a consensus on the quality of thermal insulation (Bozsaky 2017, 2018).

If the material to be used for heat insulation purposes is in paint, then the adhesion of the paint with material is the most important criteria. The adhesion resistance values of protective layers may vary depending on weather conditions, the properties of the resin used, and its molecular dimensions. The number of layers in the applications, the varnish, and the modification of the paints are also important. In addition, it has been reported that the adhesion resistance of the protective layers may vary depending on their material density and surface hardness (Budakci and Sonmez 2010; Dilik et al. 2015). Especially in recent years, by means of the production of protective layers with nano technological products, new developments have been encountered. There is a higher surface area and a higher increase in molecule ratios per head in these developments (Dongguang et al. 2002). This may contribute positively to the adhesion resistance of nano-technological protective layers. As a matter of fact, it has been reported that the adhesion resistance may decrease with mixing some additives (Panchenko et al. 2018). Various protective layers with different adhesion resistance values have been applied to different wood material surfaces: on cellulosic based (1.86 to $3.62 \mathrm{MPa}$ ), on synthetic based (3.72 to $5.43 \mathrm{MPa}$ ), on waterbased (1.44 to $3.73 \mathrm{MPa}$ ), on polyurethane based (2.37 to $4.05 \mathrm{MPa})$, and on acrylic based (3.66 to $3.80 \mathrm{MPa}$ ). Adhesion resistance values differ in the literature (Ozcifci and Ozpak 2008; Atar and Peker 2010; Dilik et al. 2015; Ozdemir et al. 2015; Sogutlu et al. 2016; Kesik et al. 2017; Oncel et al. 2019).

The aim of this study was to determine the effects of applying water-based insulation paint to laminate floorings with different numbers of layers $(2,4$, and 6$)$ in order to determine their thermal conductivity and adhesion resistance. In addition, this research aimed to determine whether insulation paint mixture can be used instead of backing paper. 


\section{EXPERIMENTAL}

\section{Materials}

High-density fiberboard (HDF)

In this study, laminate flooring based on HDF, which is widely used in flooring, was preferred as a test material because of its direct primability and coating and polishing ability. Two different laminate floorings used in the experiments were manufactured by SFC Plant, Kastamonu, Turkey. According to the relevant standards, the laminate flooring was coated with backing paper on one of the plates to be laminated, and the other surface was specially produced with $350 \mathrm{~N} / \mathrm{cm}^{2}$ press pressure in dimensions of $2070 \times 2610 \mathrm{~mm}$ without covering the surface with backing paper. The backing paper used was $150 \mathrm{~g} / \mathrm{m}^{2}$, and overlay paper was $140 \mathrm{~g} / \mathrm{m}^{2}$. After pressing, the average density value was determined to be $0.96 \mathrm{~g} / \mathrm{cm}^{3}$ in coated laminate flooring with backing paper, and $0.95 \mathrm{~g} / \mathrm{cm}^{3}$ in the uncoated laminate floorings (TS EN 323 1999). The pre-press backing paper (a) and the laminate without backing paper (b) within the parquet elements are shown in Fig. 1. In Fig. 2 , it is possible to observe the elements of laminate flooring with (a), without (b) the backing paper and a test sample, and (c) following paint application.

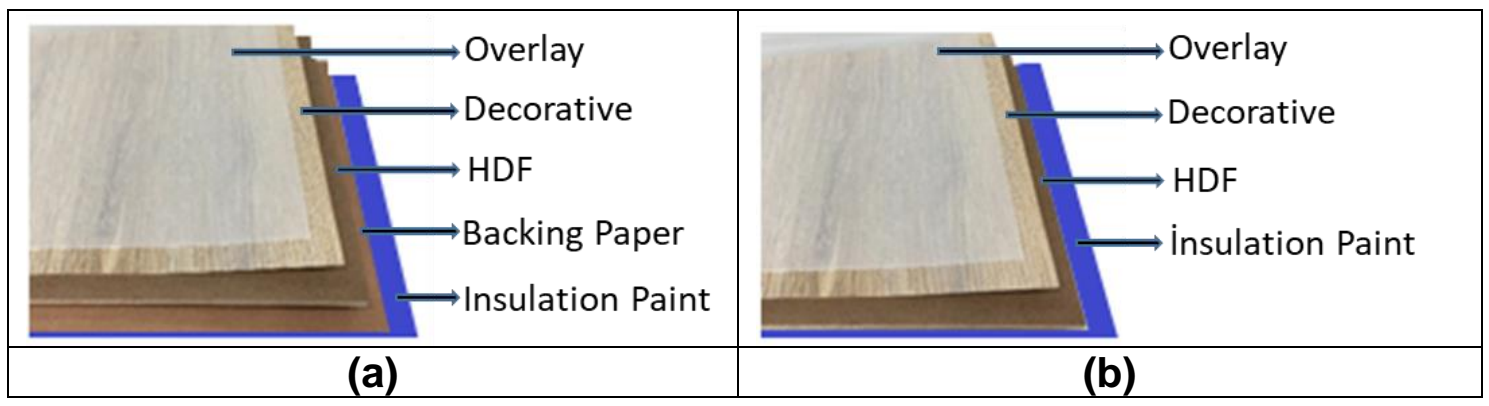

Fig. 1. Before pressing the laminate flooring elements with (a) and without (b) backing paper

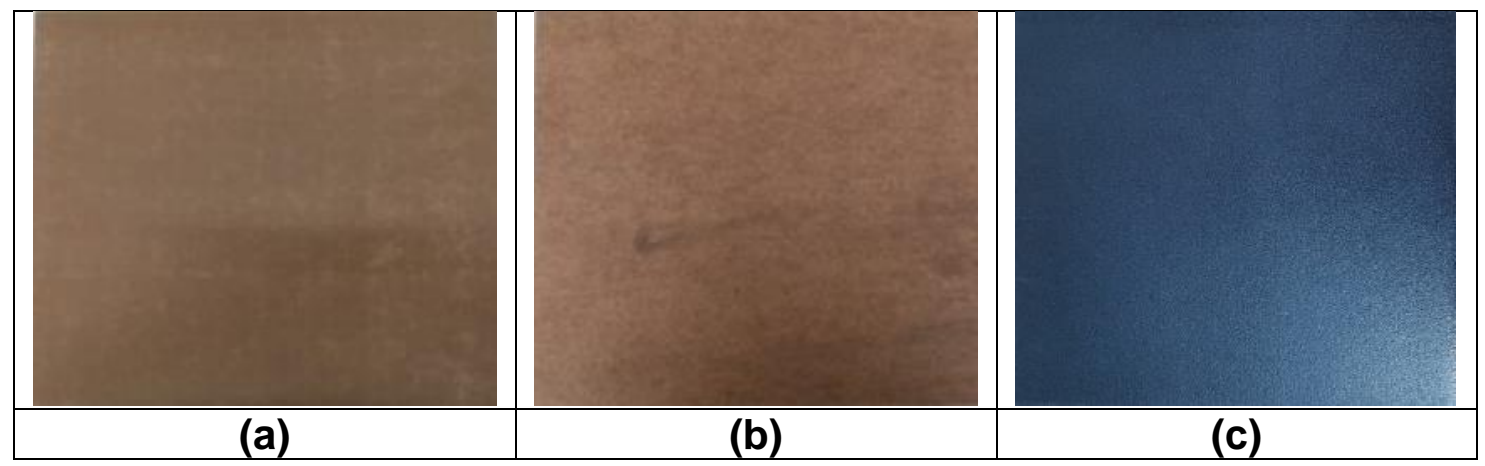

Fig. 2. After pressing the laminate flooring with (a), without (b) backing paper, and painted test sample (c)

\section{Water-based covering agents}

Water-based filler varnish (WBF-D45), water-based topcoat varnish (WBV-D45), and water-based heat-insulating paint mixed with hollow glass spheres (WBTP-D45) are the materials that were used in the experiments. The sourcing company (Kimetsan Co., Ltd., Ankara, Turkey) had defined the paint as water-based nano and micro technological insulating paint (WBNTP-D45) with the property to make micro-acrylic modified 
polyurethane insulation that was heat and water proof. The paint was prepared by mixing acrylic modified polyurethane nano-size resin $(70 \%)$ with micro-size hollow glass spheres (30\%). The technical specifications of the paints, varnishes and applications used in the study are given in Table 1 (Technical Bulletin. 2018).

Table 1. Technical Specifications Used Agents and their Applications Parameters

\begin{tabular}{|l|c|c|c|c|c|}
\hline $\begin{array}{c}\text { Protective Layer } \\
\text { Type }\end{array}$ & $\mathrm{pH}$ & $\begin{array}{c}\text { Density } \\
\left(\mathrm{g} / \mathrm{cm}^{3}\right)\end{array}$ & $\begin{array}{c}\text { Viscosity } \\
(\mathrm{s} / \mathrm{DINCup} / 4 \mathrm{~mm})\end{array}$ & $\begin{array}{c}\text { Nozzle Gap } \\
(\mathrm{mm})\end{array}$ & $\begin{array}{c}\text { Working Pressure } \\
\text { (Bar) }\end{array}$ \\
\hline WBF-D45 & 9.17 & 1.014 & 18 & 1 & 2 \\
\hline WBV-D45 & 9.10 & 1.015 & 18 & 1 & 2 \\
\hline WBTP-D45 & 8.20 & 0.82 & 30 & 2 & 2 \\
\hline
\end{tabular}

The SEM image of the large and small microscale hollow glass spheres in the paint is shown in Fig. 3, and the SEM (Quanta FEG 250; FEI Company, Brno, Czech Republic) at) image of the WBTP-D45 applied to the test sample is given in Fig. 4. All SEM images were captured at Kastamonu University Central Research Laboratory with the test specimens.

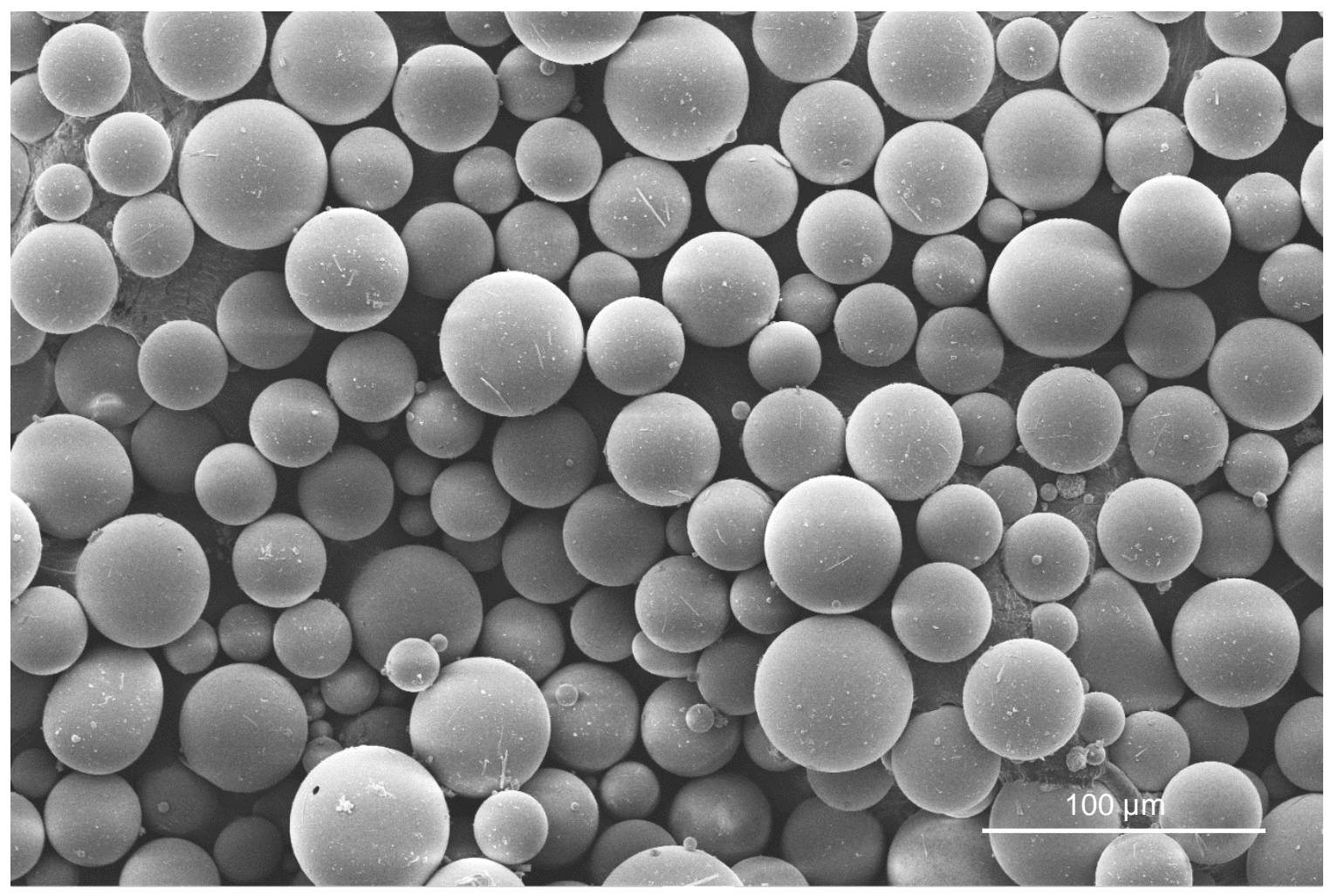

Fig. 3. SEM image of hollow glass spheres

\section{Preparation of experiments}

Test specimens prepared in the dimensions of $310 \times 310 \mathrm{~mm}$ had been kept in an air conditioning cabinet at a temperature of $20 \pm 2{ }^{\circ} \mathrm{C}$ with a relative humidity of $65 \pm 5 \%$ until they reached a constant weight (TS 2471 2005). The test specimens to be used in surface adhesion were prepared as $100 \times 100 \times 8 \mathrm{~mm}$ tests and 80 were prepared at $300 \times$ 
$300 \times 8 \mathrm{~mm}$ for thermal conductivity tests. According to the company recommendations, WBTP-D45 laminate was first applied as a layer, and WBF-D45 was used for filling to provide good bonding with parquet lining surfaces. For the second application, WBTPD45 was applied 2, 4, and 6 times separately for both coated and uncoated groups of samples. For the final application, WBV-D45 was applied as a coat to the upper surface of each sample to prevent surface abrasion and contamination. The samples were coated with paints and varnishes according to company specifications and ASTM-D 3023-98 (2011) values.

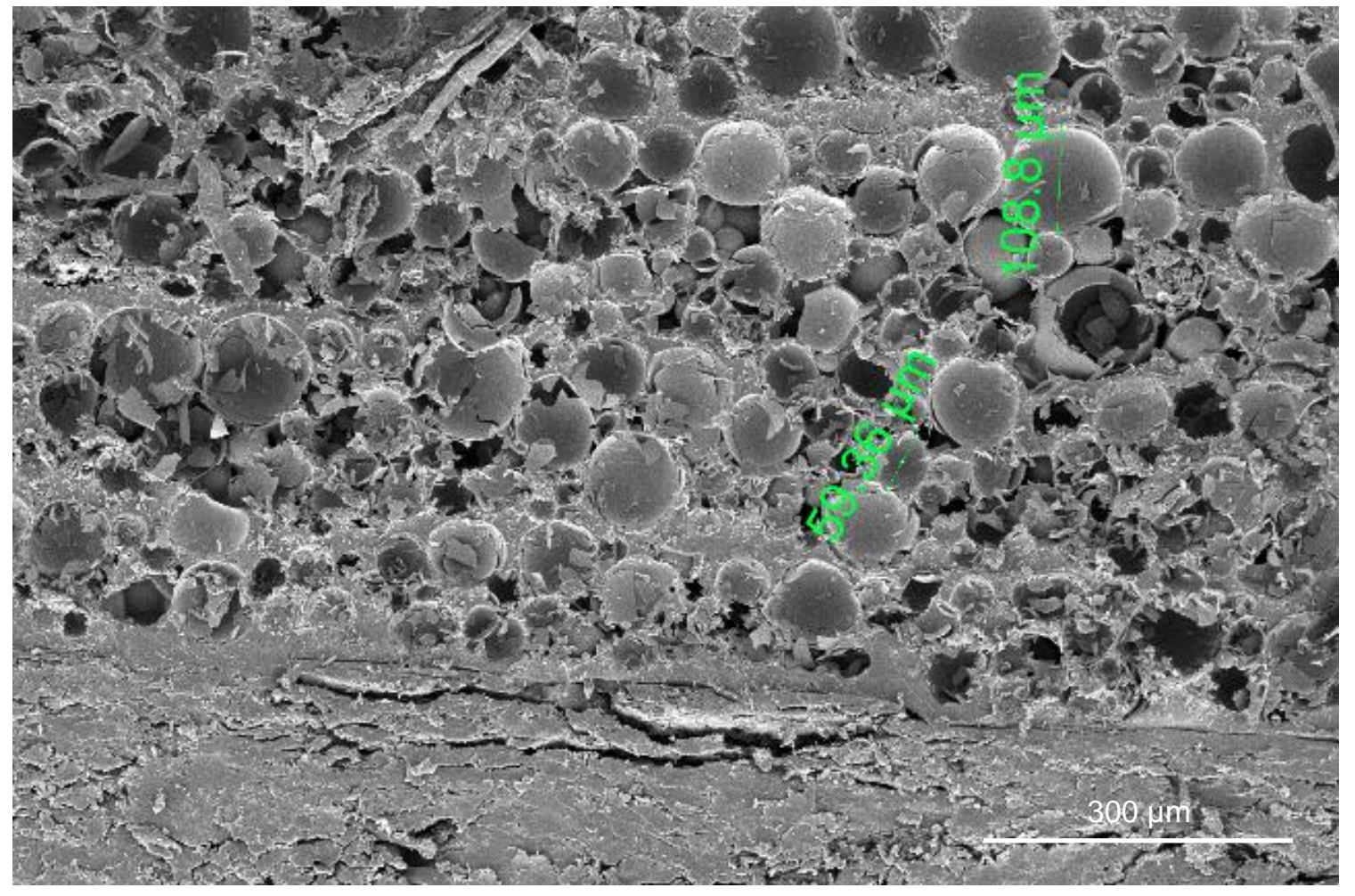

Fig. 4. SEM image of the WBTP-D45 applied to the test sample

The WBTP-D45 application was made in layers with 15 min between each layer application. The hollow glass spheres were added to the paint surface and mixed well before each application. Oven dried WBTP-D45 film thicknesses were measured as nearly $60 \mu \mathrm{m}$. Paint applications were made with a spray gun (Fig. 5) with a Fuji brand bag type compressor (Fuji Q4 Gold Tribune; Fuji Industrial Spray Equipment Ltd., Toronto, ON, Canada) and high volume low pressure (HVLP).

Thermal conductivity tests were conducted according to TS EN 12627 (2003) in the testing laboratory of the Department of Woodworking Industrial Engineering of Gazi University Faculty of Technology with a Linseis HFM 300 tester (Linseis Messgerate $\mathrm{GmbH}$, Selb, Germany). The top plate temperature of the device calibrated to $30{ }^{\circ} \mathrm{C}$ and the bottom was set to $20^{\circ} \mathrm{C}$, and the painted surfaces of the test specimens were placed between the plates and thermal conductivity coefficient values were determined by means of computer software. 


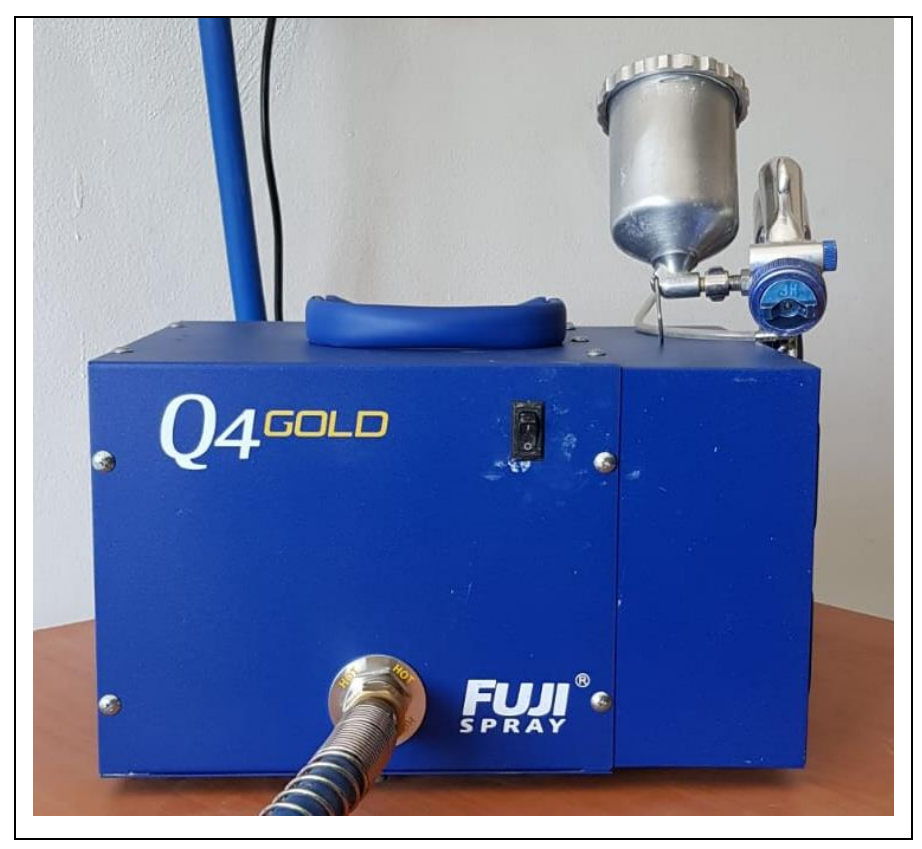

Fig. 5. Bag type compressor and spray gun with HVLP feature

For surface adhesion tests, steel cylinders with a diameter of $20 \mathrm{~mm}$ were glued to the painted surfaces of the test specimens with $150 \pm 10 \mathrm{~g} / \mathrm{m}^{2}$ double component epoxy in $20 \pm 2{ }^{\circ} \mathrm{C}$ media and left to dry for $24 \mathrm{~h}$. Then, the steel rollers adhered to the paint layer were cut to the surface of the sample with a circular knife and tests were performed. Surface adhesion tests were conducted according to ASTM D4541-02 (2009) by a Shimadzu universal test instrument (AG-IC 20KN/50KN; Shimadzu Suzhou Instruments Wfg. Co., Ltd., Suzhou, Jiangsu, China) in the laboratory of the Department of Forest Industry Engineering of Faculty of Forestry of Kastamonu University (Kastamonu, Turkey).

\section{Evaluation of data}

Statistical evaluations and analysis of thermal conductivity and dye adhesion resistance data obtained from laminated flooring of heat-insulating paint were performed using IBM SPSS 20 package (IBM Corp., Armonk, NY, USA). While this data was taken into consideration separately, analysis of variance (ANOVA) was carried out to determine the effects of the factors of backing paper usage and the number of dye layers on laminate parquet lining surfaces; the Duncan test was applied to determine homogeneous groups according to the results of bilateral interaction.

\section{RESULTS AND DISCUSSION}

\section{Thermal Conductivity Coefficient $(\lambda)$}

The results of ANOVA based on the effect of availability of backing paper (ABP) and number of dye layers (PLN) on the thermal conductivity coefficient of laminate parquet lining surfaces are given in Table 2. 
Table 2. Results of Variance Analysis on the Effect of ABP and PLN on Thermal Conductivity and Permeability Coefficient

\begin{tabular}{|c|c|c|c|c|c|}
\hline Source of Variance & $\begin{array}{c}\text { Degrees of } \\
\text { Freedom }\end{array}$ & $\begin{array}{c}\text { Sum of } \\
\text { Squares }\end{array}$ & $\begin{array}{c}\text { Mean } \\
\text { Square }\end{array}$ & F Value & $\begin{array}{c}\text { Level of } \\
\text { Significance }\end{array}$ \\
\hline $\mathrm{ABP}$ & 1 & 0.002 & 0.002 & 218.231 & $0.000^{*}$ \\
\hline $\mathrm{PLN}$ & 3 & 0.002 & 0.001 & 108.011 & $0.000^{*}$ \\
\hline $\mathrm{ABP} \times \mathrm{PLN}$ & 3 & 0.0000781 & 0.000026 & 3.768 & $0.014^{*}$ \\
\hline Error & 72 & 0.000 & 0.00000691 & & \\
\hline Total & 80 & 1.023 & & & \\
\hline * Important to $\mathrm{p}<0.05$ & \multicolumn{7}{|l|}{} \\
\hline
\end{tabular}

According to Table 2, adhesion resistance values of ABP, PLN, and the double interaction of the main variables were found to be statistically significant $(\mathrm{p}<0.05)$. Duncan test results, mean values and homogenous groups of the effects of ABP and PLN interactions are given in Table 3.

Table 3. Duncan Test Results Regarding the Effect of the Thermal Conductivity Coefficient of the ABP and PLN Binary Interaction

\begin{tabular}{|c|c|c|c|c|c|}
\hline \multirow[t]{2}{*}{$\mathrm{ABP}$} & \multirow[t]{2}{*}{ PLN } & \multirow[t]{2}{*}{$\mathrm{N}$} & \multicolumn{2}{|c|}{$\begin{array}{l}\text { Thermal conductivity coefficient }(\lambda) \\
\text { W/mK }\end{array}$} & \multirow[t]{2}{*}{ LSD } \\
\hline & & & Mean ( \pm Std. Dev.) & $H G$ & \\
\hline \multirow[t]{4}{*}{ With backing paper } & Control & 10 & $0.115( \pm 0.003)$ & C & \multirow{8}{*}{ \pm 0.003} \\
\hline & 2 & 10 & $0.111( \pm 0.001)$ & d & \\
\hline & 4 & 10 & $0.105( \pm 0.003)$ & $\mathrm{e}$ & \\
\hline & 6 & 10 & $0.104( \pm 0.003)$ & $\mathrm{e}$ & \\
\hline \multirow[t]{4}{*}{ Without backing paper } & Control & 10 & $0.126( \pm 0.004)$ & $a$ & \\
\hline & 2 & 10 & $0.120( \pm 0.001)$ & $\mathrm{b}$ & \\
\hline & 4 & 10 & $0.114( \pm 0.002)$ & $\mathrm{C}$ & \\
\hline & 6 & 10 & $0.110( \pm 0.002)$ & d & \\
\hline
\end{tabular}

According to Table 3, the highest coefficient of thermal conductivity was obtained at the control samples. The lowest thermal conductivity values were obtained in the samples covered with backing layer with the 6 layer applications. In the study conducted with QTM-500 Kyoto device by Acik and Tutus (2012), the thermal conductivity coefficient $(0.246 \mathrm{~W} / \mathrm{mK})$ in the 8 -mm-thick HDF samples coated with only one surface melamine resin decor paper is approximately two times $(0.126 \mathrm{~W} / \mathrm{mK})$ higher than the findings of this study. This difference can be caused by measurement with different devices (QTM-500 Kyoto). In a study conducted by Chukhlanov et al. (2017), with hollow glass micro-spherical filler thermal insulation dyes has given the conductivity coefficient range between 0.10 to $0.18 \mathrm{~W} / \mathrm{mK}$. Also Chukhlanov et al. (2017) suggested at least $5 \mathrm{~mm}$ thickness dye thickness for adequate heat insulation. In this study, the thickness of WBTPD45 was $360 \mu \mathrm{m}$ (for 6 layers), in which the thermal conductivity coefficient ranged from 0.104 to $0.110 \mathrm{~W} / \mathrm{mK}$. This is important in terms of the reliability of the WBTP-D45, so that it is not necessary to apply excess thicknesses. In addition, when the hollow glass spheres ratio is increased in the WBTP-D45 (30\% micro size hollow glass spheres and 70\% nano size acrylic modified polyurethane resin), the thermal conductivity coefficient is reduced. This view is supported by Dzyazko and Konstantinovsky (2014) and Wang et al. (2014). They indicated that when the porosity is increased in the paint, thermal 
performance is increased. The change in the thermal conductivity coefficient according to ABP and PLN is given in Fig. 6.

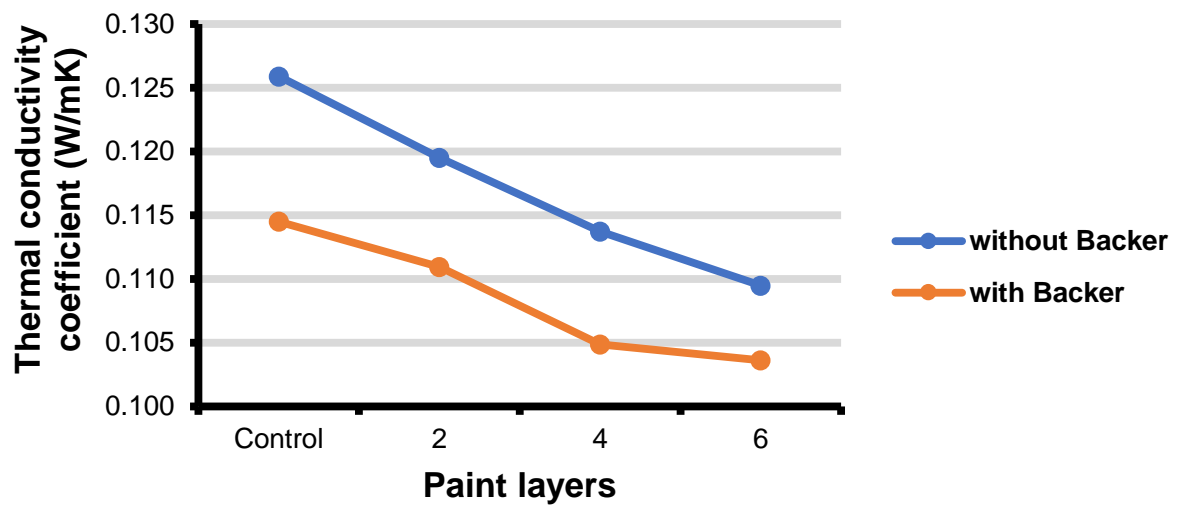

Fig. 6. Change of thermal conductivity coefficient in flooring specimens $w /$ and w/out backing paper

In general, the mean value of thermal conductivity coefficient of the test specimens covered with backing paper was significantly higher than those without backing paper (Fig. 6). In particular, the results indicated that the application of backing paper significantly affects the thermal conductivity coefficient of laminated floorings. Results showed that thermal conductivity was drastically improved with the application of backing paper. Therefore, this result indicates how important it is to use the backing paper even if the insulating paint mixture is utilized. In the literature, it is claimed that thermal conductivity coefficient values of composite materials treated with different coatings and preservatives have been changed positively (Acik and Tutus 2012; Ustaomer and Usta 2017; Sahin and Dongel 2018). This study proved to be compatible with the literature.

\section{Surface Adhesion Resistance}

The results of ANOVA based on the effect of availability of backing paper (ABP) and number of paint layers (PLN) on the adhesion resistance of laminate parquet lining surfaces are given in Table 4.

Table 4. Results of Variance Analysis on the Effect of Adhesion Resistance of ABP and PLN

\begin{tabular}{|c|c|c|c|c|c|}
\hline Source of Variance & $\begin{array}{c}\text { Degrees of } \\
\text { Freedom }\end{array}$ & $\begin{array}{c}\text { Sum of } \\
\text { Squares }\end{array}$ & $\begin{array}{c}\text { Mean } \\
\text { Square }\end{array}$ & F Value & $\begin{array}{c}\text { Level of } \\
\text { Significance }\end{array}$ \\
\hline ABP & 1 & 10.061 & 10.061 & 152.846 & $0.000^{*}$ \\
\hline PLN & 2 & 8.214 & 4.107 & 62.389 & $0.000^{*}$ \\
\hline ABP $\times$ PLN & 2 & 122 & 0.061 & 0.927 & 0.402 \\
\hline Error & 54 & 3.555 & 0.066 & & \\
\hline Total & 60 & 562.732 & & & \\
\hline * Important to $p<0.05$
\end{tabular}

According to Table 4, the adhesion resistance values of the main variables ABP and PLN were statistically significant and the pair interaction was statistically insignificant $(p<0.05)$. Duncan test results of adhesion resistance of ABP and PLN are given in Table 5 . 
Table 5. Duncan Test Results on the Adhesion Resistance of ABP and PLN

\begin{tabular}{|c|c|c|c|c|c|}
\hline \multirow{2}{*}{\multicolumn{2}{|c|}{ Operations }} & \multirow[t]{2}{*}{$\mathrm{N}$} & \multicolumn{2}{|c|}{ Bonding Strength (MPa) } & \multirow[t]{2}{*}{ LSD } \\
\hline & & & Mean ( \pm Std. Dev.) & $\mathrm{HG}$ & \\
\hline \multirow[t]{2}{*}{ ABP } & with backing paper & 30 & $3.41( \pm 0.46)$ & $a$ & \multirow[t]{2}{*}{ \pm 0.23} \\
\hline & without backing paper & 30 & $2.59( \pm 0.45)$ & $\mathrm{b}$ & \\
\hline \multirow[t]{3}{*}{ PLN } & 2 & 20 & $2.59( \pm 0.47)$ & $\mathrm{C}$ & \multirow{3}{*}{ \pm 0.32} \\
\hline & 4 & 20 & $2.93( \pm 0.51)$ & $\mathrm{b}$ & \\
\hline & 6 & 20 & $3.49( \pm 0.61)$ & $\mathrm{a}$ & \\
\hline
\end{tabular}

According to Table 5, the adhesion resistance value was determined to be high in the laminate flooring coated with balancing paper on the primer surfaces, and low in the uncoated laminate flooring for the lining surfaces. The high adhesion resistance of WBTPD45 applied to the laminate flooring coated with balancing paper on the primer surfaces may be due to the surface quality, density, hardness of the surface of the primer, and its strong bonding with the backing paper. The adhesion resistance of WBTP-D45 was determined to be the highest in the 6 layer applications (3.49 MPa) and the lowest in the 2 layer applications (2.59 MPa). In the literature, the adhesion resistance values of the different protective layers such as paint and varnish were reported to be between $2.97 \mathrm{MPa}$ and 3.73 MPa (Ozcifci and Ozpak 2008; Atar and Peker 2010; Dilik et al. 2015; Ozdemir et al. 2015; Sogutlu. et al. 2016; Kesik et al. 2017). As seen, these results support this statement as well. This compatibility can be due to the fact that the concentration of $30 \%$ hollow glass spheres in the WBTP-D45 is strongly bonded with the resin and penetrates into the depths of the wood. In particular, the ratio of glass spheres with resin to good adhesion resistance is good. This result shows that the adhesion resistance will not change with the addition of $1 / 3$ hollow glass spheres (Aznar et al. 2006), depending on the increase in filler concentration (Panchenko et al. 2018). The change of the adhesion resistance according to ABP and PLN is given in Fig. 7.

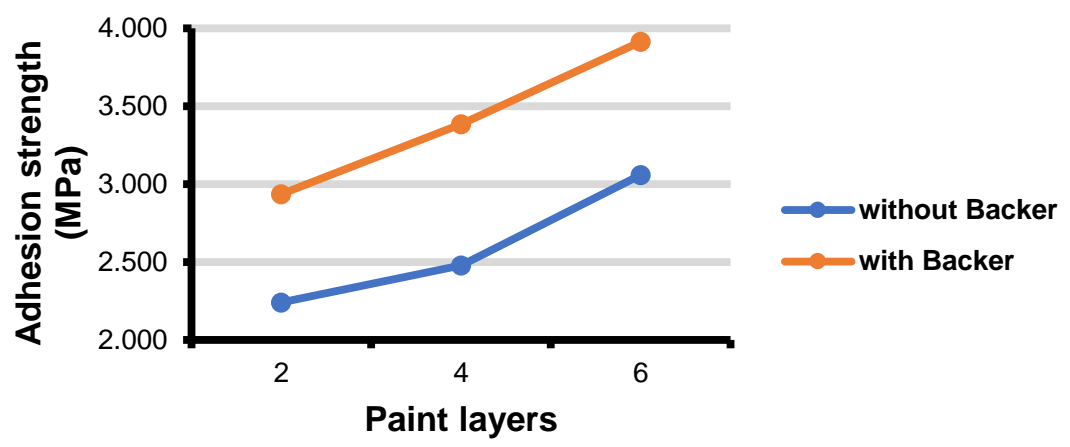

Fig. 7. Change of adhesion resistance to ABP and PLN

In general, the test samples without backing paper on the primer surfaces resulted in lower adhesion strength compared to the test samples covered with the backing paper within each paint layer (Fig. 7). It is possible to claim that the effect of backing paper on adhesion resistance is important. The test samples without backing paper applied to the 6 layer paint of WBTP-45 and the test samples covered with the backing paper applied to the 2 layer paint gave values close to each other. The adhesion strength values in the samples with backing paper on the 2-layer painted laminated parquet were close to the one without 
backing paper on the 6-layer painted laminated parquet. Therefore, it could be deduced that there is no need to use paint layers on the laminated parquet because the backing paper with two layers is enough to cover the rest.

\section{CONCLUSIONS}

1. Water-based insulation paint applied to the primer surfaces of laminate flooring produced with backing paper demonstrated a positive difference and it will increase the thermal insulation properties.

2. WBTP-D45 showed positive effects on the thermal conductivity coefficients of the laminate floorings. Depending on the insulation requirements, the extra glass bead addition and up to 750 micron thickness in WBNTP-D45 applications could be tried in new studies. It is understood from this study that WBNTP-D45 applications contribute to the thermal insulation of primer surfaces of laminated flooring in the sector with different methods.

3. Water-based insulation paint adhesion values were higher in the samples covered with the backing paper on the primer surfaces of laminate flooring. The application of WBTP-D45 at least 6 times (average 360 micrometer) on the primers of laminated flooring may be beneficial.

4. WBTP-D45 applications has not been seen effective against warping of the samples when used instead of backing paper.

5. If it is desired to have higher adhesion values on laminate floorings, it may be beneficial to perform transparent varnish applications on a WBTP-D45 at each layer.

6. Depending on the insulation and adhesion requirements, different WBTP-D45 dosages and different ratios of the hollow glass spheres in the covering agents should be recommended for further studies.

\section{ACKNOWLEDGMENTS}

This study is produced from a master's thesis (Kabakci 2018). The Hardness, Adhesion and Thermal Insulation Properties of Water-Based Paint Applied as a Wood Layering Coating MSc. Thesis, Kastamonu University) supervised by Dr. Haci Ismail Kesik. We thank Kimetsan and SFC companies for their material support.

\section{REFERENCES CITED}

Acik, C., and Tutus, A. (2012). "Effects of various synthetic surface coatings on thermal conductivity of fiberboard," Düzce University Journal of Forestry 8(2), 1-8.

As, N. (1998). "From the temple of the Hebrew King Salamon to our halls," Parquet, Floor, Floor Covering Industry Magazine (1), 1-4.

ASTM D3023 (2011). "Standard practice for determination of resistance of factory applied coatings on wood products to stains and reagents," ASTM International, West Conshohocken, PA, USA. 
ASTM D4541-17 (2009). "Standard test method for pull-of strength of coatings using portable adhesion testers," ASTM International, West Conshohocken, PA, USA.

Atar, M., and Peker, H. (2010). "Effects of impregnation with boron compounds on the surface adhesion strength of varnishes used woods," African Journal of Environmental Science and Technology 4(9), 603-609. DOI: 10.5897/AJEST10.105

Aznar, A. C., Pardini, O. R., and Amalvy, J. I. (2006). "Glossy topcoat exterior paint formulations using water-based polyurethane/acrylic hybrid binders," Progress in Organic Coatings 55, 43-49. DOI: 10.1016/j.porgcoat.2005.11.001

Bozsaky, D. (2017). "Thermodynamic tests with nano-ceramic thermal insulation coating," Pollack Periodica 12(1), 135-145. DOI: 10.1556/606.2017.12.1.11

Bozsaky, D. (2018). "Series of experiments with thermal insulation coatings consisted of vacuum-hollow nano-ceramic microspheres," Acta Technica Jaurinensis 11(1), 1733. DOI: 10.14513/actatechjaur.v11.n1.447

Budakci, M., and Sonmez, A. (2010). "Determining adhesion strength of some wood varnishes on different wood surfaces," Journal of the Faculty of Engineering and Architecture of Gazi University 25(1), 111-118.

Chukhlanov, V. Y., Trifonova, T. A., Selivanov, O. G., Ilina, M. E., and Chukhlanova, N. V. (2017). "Thin-film coatings based on hollow inorganic microsheres and polyacrylic binder," International Journal of Applied Engineering Research 12(7), 1194-1199. DOI: $10.37622 / 000000$

Dilik, T., Erdinler, S., Hazır, E., Koç, H., and Hiziroglu, S. (2015). "Adhesion strength of wood based composites coated with cellulosic and polyurethane paints," Hindawi Publishing Corporation Advances in Materials Science and Engineering 2015, Article ID 745675. DOI: 10.1155/2015/745675

Dongguang, W., Rajesh, D., and Robert, P. (2002). "Mixing and characterization of nanosized powders: An assessment of different techniques," Journal of Nanoparticle Research 4, 21-41. DOI: 10.1023/A:1020184524538

Dongel, N., Kureli, I., and Sogutlu, C. (2008). "The effect of dry heat for the colour and gloss changes on the wood and wood based floor covering materials," Journal of Politechnic 11(3), 255-263.

Dzyazko, Y. S., and Konstantinovsky, B. Y. (2014). "Thermal insulating materials," in: Structural Properties of Porous Materials and Powders Used in Different Fields of Science and Technology, Springer-Verlag, London, UK, pp. 103-128. DOI: 10.1007/978-1-4471-6377-0.

Kabakc1, A. (2018). The Hardness, Adhesion and Thermal Insulation Properties of Water-Based Paint Applied as a Wood Layering Coating (MSc. Thesis, Kastamonu University).

Kaymakcı, A., Ayrılmış, N., and Akbulut, T. (2014). "An ecological approach to facade cladding: Wood polymer composites," in: $7^{\text {th }}$ National Roofing \& Facade Symposium, Yildiz Technical University, Istanbul, Turkey, pp. 67-73.

Kesik, H. I., Ozkan, O. E., and Oncel, M. (2017). "Characteristics of a protective layer on oil heat-treated scots pine and fir wood," BioResources 12(2), 3067-3075. DOI: 10.15376/biores.12.2.3067-3075

Kimetsan (2018). Technical Brochure: Water Based Nano Insulation Coating, Kimetsan, Ankara, Turkey.

Lan, W., Kexing, F., Liang, Y., and Botao, W. (2014). "The application of ceramic coatings in petroleum chemical and building industries," in: Proceedings of the 
International Conference on Material and Environmental Engineering (ICMAEE 2014), Tianjin University, Atlantis Press, Tianjin, China, pp. 146-149.

Nemli, G., and Kalaycioglu, H. (2002). "Effects of surface coating materials on the thermal conductivity and combustion properties of particleboard," Turkish Journal of Agriculture and Forestry 26(3), 155-160.

Oncel, M., Vurdu, H., Kaymakci, A., Ozkan, O. E., and Aydogan, H. (2019). "Coating performances of crimean juniper (Juniperus excelsa M. BIEB.) wood," Cerne 25(1), 36-43. DOI: 10.1590/01047760201825012599

Ozcifci, A., and Ozpak, A. S. (2008). "Impacts of impregnation solutions on the adhesion strength of outer usage varnish coatings," Construction and Building Materials 22(4), 513-520. DOI: 10.1016/j.conbuildmat.2006.11.009

Ozdemir, T., Hiziroglu, S., and Kocapinar, M. (2015). "Adhesion strength of cellulosic varnish coated wood species as function of their surface roughness," Hindawi Publishing Corporation Advances in Materials Science and Engineering 2015, 1-5. DOI: $10.1155 / 2015 / 525496$

Panchenko, J., Akulova, M., and Panchenko, D. (2018). "Thermal insulation coating based on waterbased polymer dispersion," MATEC Web of Conferences 143, 1-5. DOI: $10.1051 /$ matecconf $/ 201814302007$

Posmyk, A. (2016). "Composite coatings with ceramic microspheres as insulating materials for transport means," Polish Society of Composite Materials 16(4), 212 217.

Sahin, H., and Dongel, N. (2018). "Determination of thermal conductivity properties of some wood and wood-based panels," in: $5^{\text {th }}$ International Furniture Congress: Proceedings Book, Eskisehir Technical University Library and Documentation Center, Faculty of Architecture and Design Publication No: 1, Eskisehir, Turkey, pp. 266-274.

Sahin Kol, H., Uysal, B., Kurt, S., and Ozcan, C. (2010). "Thermal conductivity of oak impregnated with some chemicals and finished," BioResources 5(2), 545-555. DOI: 10.15376/biores.5.2.545-555

Sogutlu, C., Nzokou, P., Koc, I., Tutgun, R., and Dongel, N. (2016). "The effects of surface roughness on varnish adhesion strength of wood materials," Journal of Coatings Technology and Research 13(5), 863-870. DOI:10.1007/s11998-016-9805-5

Oztin, C. (2010), Technical Report 1 (Technical Report No: 2010.03.04.189), METU Department of Chemical Engineering, Ankara, Turkey.

Oztin, C. (2014), Technical Report 2 (Technical Report No: 2014.03.04.795), METU Department of Chemical Engineering, Ankara, Turkey.

TS 2471 (2005). "Wood, determination of moisture content for physical and mechanical tests," Turkish Standards Institute, Ankara, Turkey.

TS EN 323 (1999). "Wood-based panels determination of density," Turkish Standards Institute, Ankara, Turkey.

TS EN 12627 (2003). "Thermal performance of building materials and products Determination of thermal resistance by means of guarded hot plate and heat flow meter methods - Products of high and medium thermal resistance," Turkish Standards Institute, Ankara, Turkey.

Ustaomer, D., and Usta, M. (2017). "Thermal conductivity of medium density fiberboard (MDF) manufactured using some chemicals," Kastamonu University of Faculty of Forestry Journal 17(4), 603-607. DOI: 10.17475/kastorman.369066 
Uysal, B., Yapici, F., Sahin Kol, H., Ozcan, C., Esen, R., and Korkmaz, M. (2011). "Determination of thermal conductivity finished on impregnated wood material," in: $6^{\text {th }}$ International Advanced Technologies Symposium (IATS'11) Proceedings Book, Elazı ğ, Turkey, pp. 262-266.

Wang, F., Liang, J., Tang, Q., Chen, C., and Chen, Y. (2014). "Preparation and performance of thermal insulation energy saving coating materials for exterior wall," Journal of Nanoscience and Nanotechnology 14(5), 3861-3867. DOI: $10.1166 /$ jnn.2014.8034

Zhou, J., Zhou, H., Hu, C., and Hu, S., (2013). "Measurement of thermal and dielectric properties of medium density fiberboard with different moisture contents," BioResources 8(3), 4185-4192. DOI: 10.15376/biores.8.3.4185-4192

Article submitted: March 26, 2020; Peer review completed: May 24, 2020; Revised version received and accepted: June 17, 2020; Published: June 22, 2020. DOI: 10.15376/biores.15.3.6110-6122 